\title{
THE THROMBOGENIC HYPOTHESIS AND ITS IMPLICATIONS
}

\author{
J. B. Duguid, M.D.
}

From the Department of Pathology, Royal Victoria Infirmary, Newcastle upon Tyne

The discovery that mural thrombi in arteries become incorporated in the intima and form fibrous thickenings has raised many new questions, some of which are at present occupying the attention of members of the Pathology Department.

\section{Factors Governing Thrombosis}

It is recognized that thrombi tend to form where there are lesions of the arterial walls and destruction of the endothelial lining has been cited as one of the determining factors. In addition, since the commonest lesion in human arteries is atherosclerosis, lipid accumulation has been cited as a possible factor.

Dr. I. Rannie ${ }^{18}$ has carried out experiments to test the thrombogenic effects of cholesterol in rabbits, and the results have been consistently negative. The arterial lesions produced by adding large quantities of cholesterol to the rabbits' food were in some instances extremely severe, yet they were never accompanied by recognizable thrombosis. They showed, in fact, that in so far as rabbits were concerned neither interruption of the endothelial lining nor the presence of cholesterol in the arterial walls were sufficient to promote thrombosis. They also showed, incidentally, that the introduction of cholesterol into the arterial intima involved a process similar to the incorporation of mural thrombi. Cholesterol-bearing phagocytes circulating in the blood were deposited on the intimal surface and in due course covered by endothelium so that they were incorporated in the vessel wall.

The effects of trauma in the arterial walls have been studied by Dr. A. R. Ghani. Pricking, tearing or even crushing the central artery of the rabbit's ear produced destructive lesions which in some instances were extremely severe, yet the results in so far as thrombosis was concerned were at first quite unpredictable. Pricking or slight tearing sometimes resulted in the production of large mural thrombi, which in due course became organized and converted into fibrous thickenings of the walls, but this process, although it amounted to healing, usually led to narrowing of the vessels, $\stackrel{\vec{D}}{\circ}$ since the thrombi occupied space in their lumina. 8 Such results, however, were by no means the rule, $\underline{3}$. for in some instances, although a clot was seen to have formed at the time of the injury, no thrombus $\rightarrow$ was to be found after a few days, some fibrino- $\vec{A}$ lytic agent having apparently removed it. It was notable, however, that in its absence the healing o process was in no wise impaired, but rather im- o proved, since there was none of the residual $\rightarrow$ narrowing which a mural thrombus produces.

In view of these findings we are forced to reassess the part played by thrombosis in the $\vec{\varphi}$ healing process. We have been accustomed to regard fibrin formation as essential to the reparf. of extensive tissue damage, but it would seem that it requires to be kept in check, and that fibrinolysis must also be regarded as a controlling factor in the repair process.

\section{The Fibrinolytic System}

Fibrinolysis depends on a proteolytic enzyme (plasmin) which is derived from a precursor (plasminogen) in the blood. The conversion of plas- $\bar{c}$ minogen to plasmin depends on a plasminogen activator which has been shown to be present in both blood and tissues. This activator is itself derived from a precursor (pro-activator) present $O$ in the blood. A ' fibrin plate' method has been devised ${ }^{17}$ for the detection of plasminogen activator 은 and Dr. A. S. Todd ${ }^{19}$ has adapted this to histology $\frac{D}{2}$ so that he can identify the sources of activator in the tissues.

Histological sections of fresh tissues are cut by the frezing method and laid on thin films of fibrin $N$ previously spread on histological slides. The pre- $\mathrm{C}$ parations are then incubated at $37^{\circ} \mathrm{C}$. for $30 \stackrel{2}{\circ}$ minutes and subsequently stained with haematoxylin, so that the tissue structures are shown against an even blue background produced by the staining of the underlying fibrin. Fibrinolytic activity is indicated by clearing of the background stain $\overrightarrow{\mathbb{D}}$ around the points where activator is produced, and $\frac{\pi}{\mathbb{D}}$ 
it is possible by this method to identify the individual cells concerned in its production.

Todd has found that the endothelial cells lining veins (and pulmonary arteries) are the main source nof activator, and this may explain the finding ${ }^{8}$ that there is a greater fibrinolytic activity in venous blood than arterial. Arterial endothelium, on the other hand, shows much less evidence of activator production, and it is only on further treatment of the tissues that evidence comes to 'light suggesting that it contains not the activator, but a pro-activator. What controls the conversion of pro-activator to activator remains to be discovered, but Todd has reason to suspect that histamine may be concerned.

The problem is of great complexity, but these findings, which, incidentally, endorse John Hunter's suggestion that the blood owes its fluidity to some action of the living vessels, seem to indicate very clearly that the endothelial cells of the blood vessels play an important part in the control of intravascular thrombosis.

\section{The Identification of Fibrin}

We now know that many of the arterial thicken, ings hitherto taken for overgrowths of the intimal connective tissues have actually been products of mural thrombosis. Our failure in the past to recognize them has been due partly to the fact that there is no very satisfactory specific stain for fibrin. Freshly formed fibrin reacts readily enough with certain dyes, but older deposits become changed in appearance and lose their specific staining properties. Fortunately, we now have in the fluorescent -antibody technique ${ }^{4,5,9}$ a, histological reagent which is highly specific. By conjugating the antiserum to fibrin with a fluorescent dye and applying it to suitably prepared sections fibrin is identifiable by the fact that it fixes its antibody and thereupon itself becomes fluorescent. This technique is now being applied by Dr. A. J. Wort to the identification of fibrin in the arterial walls.

In the conversion of mural thrombi into fibrous thickenings there is a stage at which the fibrin acquires a hyaline appearance and looks like swollen connective tissue. There is reason to suspect that some observers have taken this appearance to represent ageing or degenerate connective tissue, and that others have cited it as an example of a collagen vascular disease, so that its identity is by no means agreed on. There are also doubts as to the mode of conversion of fibrin into fibrous tissue, it being uncertain whether this involves an actual metamorphosis of fibrin to collagen or a removal of the fibrin and replacement of it by collagen. It has been suggested ${ }^{14}$ that fibrin is actually changed, and if this is so it would be interesting to know at what state it loses its antigenic specificity.

These are some of the questions which Wort is attempting to answer, but the most important of all concerns the incidence of fibrinous deposits in arteries. Thin layers of fibrin are quite frequently seen in the intimal surface of the aorta and coronary arteries, and it is fairly clear that some of them are converted into thickenings of the intima. Some of them, however, are so thin as to be hardly detectable by ordinary histological methods and it may be that improved methods will show them to be much commoner than is now apparent. It has been suggested ${ }^{3}$ that fibrin is constantly being laid down on the walls of blood vessels and constantly removed by fibrinolytic agents, and it has further been suggested ${ }^{11}$ that the permeability of the vessels may depend on this, the idea being that there is a dynamic equilibrium between the fibrinogenic and the fibrinolytic factors in the body controlling it. There is also the possibility that the normal increase in thickness of the intima from childhood to old age in the aorta and coronary arteries may depend on the laying down of fibrin on the intimal surface. Wort has commonly noted fluorescence in the subendothelial layers of arteries, but since there are so many factors to be controlled in the fluorescent antibody technique it is still far from established that this represents a fibrinous deposit.

\section{Cells in Organization}

The histology of mural thrombosis provides abundant evidence that cells play an essential part in the fibrous tissue formation in organization, but the origin and identity of the cells concerned is still a question. In organizing mural thrombi fibrous tissue first makes its appearance in the neighbourhood of certain spindle-shaped cells which are termed fibroblasts and which are assumed to have been derived from the neighbouring connective tissues of the vessel wall. In larger mural thrombi endothelial-lined channels also appear and they are assumed to be extensions of the endothelium lining the lumen of the artery or of the vasa vasorum. Sometimes, however, in large thrombi, fibroblast-like cells and vascular channels having no connection with the surrounding tissues ${ }^{6}$ are found, and there is the suspicion, therefore, that organization may sometimes originate from the indigenous cells of the thrombus.

Practically all mural thrombi have blood cells entangled amongst the fibrin of which they are mainly composed, and one can sometimes gauge their age by the cells which predominate. Newly formed thrombi usually have leucocytes of all kinds, including polymorphs, whereas in older ones the polymorphs have died off, leaving a few cells, 
apparently of the monocyte class, scattered here and there. In still older thrombi many of the cells are spindle shaped, of the kind called fibroblasts, and, since they have much the same distribution as the monocytes of earlier examples, it looks as if they might be the same cells changed morphologically.

In order to study these indigenous cells of thrombi Ghani has implanted autogenous fibrin clots, enclosed in semi-permeable capsules, into the subcutaneous tissue of rabbits in such a way as to allow the permeation by body fluids, while preventing the invasion of cells from outside. He has found that, whilst the polymorphs included in the clots die within two or three days, the mononuclears survive indefinitely. After three or four weeks new cells appear in the clots, some of them spreading over the surfaces of the fibrin masses and others embedded in the masses and resembling fibroblasts or macrophages, whilst in one or two instances spindle cells have been found arranged in parallel formations suggesting primitive capillaries. These new cells must presumably have been derived from the leucocytes included in the fibrin when the clots were formed, and their appearance seems to confirm the suspicion expressed by many authorities that the cells of the circulating blood have the potentialities for both endothelial and connective tissue formation.

\section{Mechanical Factors in Atherosclerosis}

In the last century authorities were inclined to regard atherosclerosis as a lesion produced by mechanical strain. The idea was based on the fact that the lesions were most commonly found in the aorta and its main branches where the force of the ventricular output bore most heavily on the arterial walls, and where pulsation was consequen.ly most marked. This, together with the fact that they occurred at bifurcations and around the openings of branches, where the vessels were most exposed to mechanical stresses, seemed to bear out the ' wear and tear' concept elaborated by Sir Clifford Allbutt.1 In I913 the trend of opinion changed when it was shown ${ }^{2}$ that arterial lesions resembling atheroma could be produced in rabbits by adding cholesterol to their food. Thereupon all attention was turned to the question of diet and the mechanical hypothesis forgotten, but recently some new information came to light which has turned our attention back to it.

Intimal haemorrhage has long been recognized as an occasional feature of atherosclerosis, 15,20 but its frequency was not realized until it was shown by a special technique ${ }^{16}$ that haemosiderin, presumably representing old haemorrhage, was a feature of most atherosclerotic lesions. By applying potassium ferrocyanide and hydrochloric acid to arterial tissues before fixation in formalin instead of after, the Prussian blue reaction was more $\varrho$ readily produced. Dr. Rannie has confirmed this $\frac{3}{\Phi}$ and found that haemorrhage is much commoner $\varrho$ in atherosclerosis than has hitherto been suspected. $\stackrel{c}{\longrightarrow}$ Further, he has confirmed our previous observation, ${ }^{7}$ that haemorrhages are commonest at points in the arterial walls where, on theoretical grounds, $\frac{\bar{\sigma}}{\sigma}$ mechanical strain is to be expected.

We have long suspected that the fibrous $\frac{\text { के }}{\overrightarrow{0}}$ thickenings, which obviously impair the elasticity of the intima, must give rise to local strains when ${ }^{\text {s }}$ the arteries expand and recoil in pulsation, but $\vec{O}$ since no specific evidence of trauma could be $\vec{\overrightarrow{ }}$ demonstrated there was no means of confirming the $\tilde{\sigma}_{\mathscr{J}}$ suspicion. The finding of haemosiderin, specificallyo located at the predicted points of strain, provides 3 the missing evidence, since it suggests that tearing of the structures actually does occur in life, and. occurs very frequently.

It has been suggested ${ }^{13,20}$ that some of the fatty debris in atheroma is derived from blood destruc- N tion and there is certainly histological evidenceo that most of the blood which is extravasated finds? its way into the atheromatous foci. So long as $>$ intimal haemorrhage was regarded as a rare을. occurrence the suggestion seemed to be of minor $\vec{P}$ importance, but now that we know it to Be\& common we have to consider the possibility tha large proportion of the fatty substances in atherō:sclerosis may be the products of recurrings haemorrhage. This aspect of the problem is beingo investigated in the aorta by Rannie and in theo cerebral arteries by Dr. J. K. Todd.

\section{Incorporation of Coal Dust in the Lungs}

One of the important principles emerging from? the study of mural thrombosis and atherosclerosis? is that the endothelium of blood vessels is not a permanent or fixed membrane, but merely a system? of cells which intervene between any solid matter'and the circulating blood. In the past we had failed to realize that solid matter adhering to the walls ofo blood vessels is eliminated from the blood stream? and added to the tissues simply by the formation? of a new covering layer. The realization of this led us to wonder if there might not be other을. examples which have been missed, not only in then vascular system, but in other lining membranes.

One of the pathological processes which it 0 occurred to us to study in this connection was thew introduction of coal dust into the lurgs. It haso been assumed that coal dust is picked up in theo lung alveoli by phagocytic cells and transported by them to the lymph channels, there to accumu $-\stackrel{?}{+}$ late and promote a fibrous overgrowth. It must be admitted that the histological appearance of lungs prepared by the ordinary technical methods 
suggests this, but these methods are by no means ideal for histological interpretation. The immersion of lung tissue in formalin or other fluid fixative causes the dust-laden phagocytes to be washed off the alveolar walls so that they lie free as if they were floating in air and had no definite relationship to the tissue structures.

Dr, E. V. Hulse, ${ }^{10}$ who worked in our department some years ago, found that a very different picture was obtained if, before opening the chest at autopsy, the trachea were clamped so as to prevent the escape of residual air. The dustbearing cells then remained on the alveolar walls in the positions they presumably occupied in life, and their relationship to dust in the tissues was then clearer. Hulse came to the conclusion, on experimental as well as morbid histological grounds, that these cells were in due course eliminated from the air spaces and incorporated in the alveolar walls simply by the formation of a new covering layer of alveolar lining cells.

His findings have been confirmed ${ }^{22}$ by $D r$. Margaret Lambert and myself. In pursuing this problem we have found that satisfactory preparations for histological purposes are obtained by inflating lungs with formaldehyde vapour so that they are expanded to something like their natural size and shape. The cellular elements then remain undisturbed by any influx of fluids, while the connective tissue structures are less deranged than in lungs which have been allowed to collapse. In inflated preparations the lymph channels are clearly defined, and we have seen no evidence of any accumulation of dust in them. Pneumoconiosis appears to be due simply to the accumulation of dust-bearing phagocytes in the alveoli and their subsequent incorporation into the alveolar walls by the formation of covering layer of alveolar lining cells.

\section{REFERENCES}

1. ALLBUTT, SIR CLIFFORD (1915), 'Diseases of the Arteries including Angina Pectoris' (London).

2. ANITSCHKOW, N., and CHALATOW, S. (1913), Zbl. allg. Path. path. Anat., 24, I.

3. ASTRUP, T. (1956), Lancet il, 565.

4. COONS, A. H., and KAPLAN, M. H. (1950), F. exp. Med., 9I, I.

5. CHADWICK, C. S., McENTEGART, M. G., and NAIRN, R. C. (1958), Lancet i, 412.

6. DIBLE, J. H. (1958), Ұ. Path. Bact., 75, I.

7. DUGUID, J. B., and ROBERTSON, W. B. (r957), Lancet i, 1205 .

8. FEARNLEY, G. R., and FERGUSON, J. (1957), Lancet it, I041.

9. GITLIN, D., LANDING, B. H., and WHIPPLE, A. (1 953), f. exp. Med., 97, 163 .

10. HULSE, E. V. (1955), F. Path. Bact., 69, 225.

II. JENSEN, H. (1956), Exper. Med. Surg., 14, 189.

12. LUCHTRATH, H. (1956), Virchows Arch.path. Anat., 329, 77.

r 3. MORGAN, A. D. (1956), 'Pathogenesis of Coronary Occlusion' (London: Blackwell).

14. MONTGOMERY, G. L. (1957-58), Lectures on the Scientific Basis of Medicine, $\mathrm{i}, \mathrm{1} 62$.

15. PATERSON, J. C. (1936), Arch. Path. (Chicago), 22, 313.

16. PATERSON, J. C., MOFFAT, T., and MILLS, J. (I 956), Arch. Path. 6r, 496.

17. PERMIN, P. M. (1947), Nature 160, 571.

18. RANNIE, I., and DUGUID, J. B. (1953), F. Path. Bact., 56, 395. 19. TODD, A. S. (1959), f. Path. Bact., 78, 28 r.

20. WINTERNITZ, M. C., THOMAS, R. M., and LeCOMPTE, P. M. (1938), 'The Biology of Atherosclerosis' (Baltimore).

\section{RUTHIN CASTLE, NORTH WALES}

A Clinic for the diagnosis and treatment of Internal Diseases (except Mental or Infectious Diseases). The Clinic is provided with a staff of doctors, nurses, technicians, modern Radiological and Physiotherapy departments.

The surroundings are beautiful. The climate is mild. There is central heating throughout. The annual rainfall is 30.5 inches, that is less than the average for England.

The Fees are inclusive and vary according to the room occupied.

For particulars apply to THE SECRETARY, Ruthin Castle, North Wales. 